\title{
Comparative Proteomic Profile of the Human Placenta in Normal and Fetal Growth Restriction Subjects
}

\author{
Zhijing Miao Min Chen Hong Wu Hongjuan Ding Zhonghua Shi \\ State Key Laboratory of Reproductive Medicine, Nanjing Maternity and Child Health Care Hospital \\ Affiliated to Nanjing Medical University, Nanjing 210004, China
}

\section{Key Words}

TMT • Fetal growth restriction • Placenta • Oxidative stress $•$ Apoptosis

\begin{abstract}
Background: Fetal growth restriction (FGR) is the main cause of intrauterine fetal death and the second leading cause of death in the neonatal period. A large body of evidence suggests that FGR may be associated with the placenta, although its etiology and pathogenesis remain to be fully elucidated. Methods and Results: To better understand the molecular mechanisms underlying the pathological development of the placenta in FGR, we used tandem mass tags (TMTs) to construct a large-scale comparative proteomic profile of human placentas from normal and FGR pregnancies. A total of 1,198 kinds of proteins were identified in the control and FGR placentas, of which 95 were differentially expressed between two groups. Ingenuity Pathway Analysis (IPA) was used to organize these differentially expressed proteins into networks of interacting proteins and to identify the modules of functionally related proteins. Western blotting was used to verify the expression patterns of several randomly selected proteins. Conclusion: The placentas of women with FGR displayed significant proteome differences compared with normal pregnancy. The results indicate that a variety of mechanisms and proteins may contribute to the development of FGR. Further studies and validations are required to elucidate the exact roles of these proteins in FGR pathogenesis.
\end{abstract}

Z. Miao and M. Chen contributed equally to this work. 


\section{Introduction}

Fetal growth restriction (FGR) is a major complication of pregnancy and affects up to $10 \%$ of all pregnancies [1]. It is the main cause of intrauterine fetal death and the second leading cause of death in the neonatal period [2]. Although the primary mechanism of FGR is still unknown, a considerable body of evidence suggests that FGR could be associated with many factors such as impaired placental function, inadequate trophoblast invasion, deficient spiral arterial remodeling, and increased apoptosis of trophoblastic cells [3-6]. Notably, recent studies have indicated that impaired placental function may hold the key to the etiology of FGR $[3,7]$.

The placenta is the interface between maternal and fetal circulation, and it plays several significant roles in pregnancy, such as transporting gases, nutrients, and waste products, preventing the rejection of fetal allografts and producing peptides and hormones [3-8]. In short, placental function holds a key to fetal development or its failure. Recent studies have made some progress in better understanding the molecular mechanisms underlying the pathological development of the placenta in patients with FGR. For example, abnormalities of trophoblast invasion and villous vascular development will lead to a failure in establishing adequate uteroplacental blood flow and may increases the risk of oxidative stress and acidosis $[9,10]$, indicating the imbalance between antioxidants and reactive oxygen species (ROS) production (oxidative stress) is a critical risk factor in FGR [11-13]. Besides, increased apoptosis was significantly observed in placenta trophoblasts, suggesting apoptosis may be one of the pathogenesis of FGR [14, 15].

Dysfunctions of several molecules, such as nicotinamide adenine dinucleotide phosphate (NADPH) oxidase, alpha-1-antitrypsin (SERPINA1), insulin-like growth factor (IGF) and vascular endothelial growth factor (VEGF), might correlate with abnormal trophoblast invasion and vascular development, and oxidative stress in the placenta of FGR subjects [16-22]. The expression levels of apoptosis associated factors, such as ATPdependent RNA helicase (DDX42), Bcl-2, p53, low-density lipoprotein (LDL), apo B and matrix metalloproteinases, changed during FGR development [6, 23-28]. However, thus far, no large-scale proteomic analyses have been used to investigate the regulatory factors involved in the placenta of pregnancies with FGR. Therefore, here, we aimed to establish a comparative proteomic profile of human placentas in normal and FGR pregnancies using TMTs.

\section{Materials and Methods}

\section{Sample preparation}

This study was conducted in accordance with the declaration of Helsinki and performed with approval from the Ethics Committee of the Nanjing Maternity and Child Health Care Hospital affiliated to Nanjing Medical University. Written informed consent was obtained from all participants.

Placental tissues were obtained from twenty pregnant women (10 cases for FGR and 10 cases for control) according to the standard operating procedure. All mothers had undergone cesarean section delivery at the Maternal and Child Health Hospital of Nanjing and had the same range of age and gestational age. FGR refers to a fetus that has failed to achieve its genetically determined growth potential and was defined as estimated fetal weight (EFW) less than the tenth percentile with respect to the reference value for current pregnancy age. The details of patient characteristics are presented in Table 1. For each placenta sample, $0.5 \mathrm{~g}$ of placental tissue was dissected from the maternal side of the placenta (in the central region excluding the calcified area), rinsed with $0.9 \%$ saline, and frozen in liquid nitrogen prior to use.

Protein extraction

Proteinminer (Aurum serum protein mini kit, Bio-Rad) before proteomic analysis was used to remove high abundance proteins to allow the visualization of low abundant proteins as previously described [29]. 
Table 1. Clinical characteristics of controls and patients with fetal growth restriction. Data are presented as the means $\pm \mathrm{SD}$. ${ }^{*} \mathrm{P}<0.05,{ }^{* *} \mathrm{P}<0.01$

\begin{tabular}{lccc}
\hline & $\begin{array}{c}\text { Controls } \\
(\mathrm{n}=10)\end{array}$ & $\begin{array}{c}\text { FGR } \\
(\mathrm{n}=10)\end{array}$ & P-value \\
\hline Maternal age (years) & $28.20 \pm 3.71$ & $26.30 \pm 2.41$ & 0.193 \\
Gravidity & $1.30 \pm 0.48$ & $1.40 \pm 0.70$ & 0.714 \\
BMI $\left(\mathrm{kg} / \mathrm{m}^{2}\right)$ & $25.06 \pm 2.96$ & $25.73 \pm 2.62$ & 0.597 \\
Gestational weeks & $38.64 \pm 1.06$ & $37.62 \pm 2.20$ & 0.207 \\
Birth weight $(\mathrm{g})$ & $3305.00 \pm 338.67$ & $1949.00 \pm 325.93$ & $<0.001^{*}$ \\
\hline
\end{tabular}

The protein was preserved at $-20^{\circ} \mathrm{C}$. The supernatant was reduced using $10 \mathrm{mM}$ dithiothreitol (DTT) at $56^{\circ} \mathrm{C}$ for $1 \mathrm{~h}$, and then alkylated by incubation with $55 \mathrm{mM}$ of iodoacetyl moiety biotin (IAM-biotin) in a dark room for $1 \mathrm{~h}$. Precooled acetone was added to the sample liquid until the total volume was five times the original volume, and the mixture was precipitated at $-20^{\circ} \mathrm{C}$ for at least $1 \mathrm{~h}$. The mixture was then centrifuged at rate of $1000 \mathrm{~g}$ for $20 \mathrm{~min}$ at $4^{\circ} \mathrm{C}$. The precipitate was added to $300 \mu \mathrm{L}$ of buffer with a final concentration of $50 \%$ Tetraethylammonium Bromide (TEAB) containing $0.1 \%$ SDS. Then, ultrasound was used to enhance homogenates and cell lysis. Finally, Bradford assay was used to quantify the protein.

\section{Protein digestion}

Placenta protein $(100 \mu \mathrm{g})$ from normal and FGR subjects was diluted with TEAB containing $0.1 \%$ SDS. Then, $3.3 \mu \mathrm{g}$ of $1 \mu \mathrm{g} / \mu \mathrm{L}$ trypsin was added, and the mixture was immersed in a $37^{\circ} \mathrm{C}$ water bath for $24 \mathrm{~h}$. Then, $1 \mu \mathrm{g}$ of trypsin was added, and the mixture was incubated in a $37^{\circ} \mathrm{C}$ water bath for $12 \mathrm{~h}$. Thereafter, the mixture was vacuum freeze-dried, and resuspended in $30 \mu \mathrm{L}$ of TEAB containing $0.1 \%$ SDS (water: TEAB = 1:1). Finally, MALDI TOF/TOF was used to check the digestive efficiency for $1 \mu \mathrm{L}$ of the lysate.

\section{Peptide labeling and depuration}

10 cases of FGR or 10 cases of control were randomly divided into 3 groups respectively, indicating the protein sample of each group was a mixture from 3 or 4 patients. The labeling reagent was equilibrated to room temperature. Then, $70 \mu \mathrm{L}$ of isopropyl alcohol was added to the labeling reagent and vortexed for 1 min. The homogenized labeling reagent was then added to the peptides, and isotopic labels of different sizes were used for the different samples. The mixture was vortexed again and equilibrated at room temperature for $2 \mathrm{~h}$. The labeled samples were then dried in vacuo and separated by HPLC and C18 reversed phase chromatography and desalted. Finally, the peptides were dissolved by adding $0.1 \%$ formic acid.

Mass spectrometry data acquisition and identification

The labeled peptides were analyzed using high-precision LC-MS (Thermo-fisher Q-Exactive Orbitrap). The MS/MS spectra acquired from precursor ions were submitted to Mascot (version 2.3.01) using the following search parameters for quantitative retrieval: the Swissprot Human Library was used for database search, the enzyme used was trypsin, urea methylation was used for fixed modification, methionine oxidation was used for variable modification, the peptide tolerance was set at $15 \mathrm{ppm}$, MS/MS tolerance was set at $20 \mathrm{ppm}$, and the maximum number of missed cleavages was 1 . Meanwhile, the following search parameters were used for qualitative analysis: the protein ratio was determined using the median value, the minimum peptides was 1 , the median normalization method was used, the p value was set at $<0.05$, and the fold change was 1.2 .

\section{Western blotting}

Western blot analysis of all twenty samples was performed as described previously [30]. Lysates from the placentas of normal and FGR subjects were separated on 15\% SDS-PAGE gels and the proteins were then transferred on to nitrocellulose membranes (Amersham Biosciences, RPR303D). The membranes were blocked in Tris-Buffered Saline and Tween 20 (TBST) containing 5\% nonfat milk powder for $1 \mathrm{~h}$, incubated overnight with primary antibodies against CSNK2B (1:3000 dilution; Abcam Ab133576, Cambridge, UK), GOSR2 (1:2000 dilution; Abcam Ab115642), HNRNPH2 (1:2000; Abcam Ab157498), SERPIN A3 (1:3000 dilution; Abcam Ab88527), SERPIN A1 (1:2000 dilution; Novus 2B12) and GAPDH (1:2000 dilution; Abcam 
Ab9485), then washed three times (10 minutes each) with TBST. The membranes were then incubated for $1 \mathrm{~h}$ with alkaline phosphatase (AP)-conjugated anti-mouse or rabbit IgG (1:1000 dilution; Promega, S372B, WI, USA). The T protein levels were evaluated by detecting alkaline phosphatase activity using a Lumi-Phos kit (Pierce Biotechnology, KJ1243353).

\section{Statistical analysis}

For dimethyl labeling, the following criteria were used to consider a protein for further statistical analysis: two or more high-confidence unique peptides could be identified, the $p$ value was $<0.1$, and the fold difference was $>1.5$ or $<0.5$. Then, the Student's $t$ test was used to find the significantly altered proteins with the SPSS software (version 18.0).

The visualized bands of the Western blot analysis were quantified with Quantity One software (BioRad). The protein ratio was determined using the median value. The Student's $t$ test was used to generate $\mathrm{p}$ values. Differences were considered significant at a $\mathrm{p}$ value of $<0.05$.

Bioinformatics analysis

Gene ontology (GO) analysis was used to determine the biological significance of the identified proteins by exploring the relationship between biological terms and genes associated with three structured ontologies including the biological process, molecular function, and cellular components. The identified proteins were divided into different categories according to biological function. Ingenuity Pathway Analysis (IPA) (Ingenuity Systems, Redwood City, CA, USA) was used to organize differentially expressed proteins into networks of interacting proteins and to identify modules of functionally related proteins involved during the pathological changes of placenta in FGR. Proteins whose expression was significantly differentially regulated (fold change $\geq 1.2$, $p$ value $\leq 0.05$ ) were selected for the analysis. A detailed description is given in the online repository (http://www.geneontology.org and http://www.ingenuity.com).

\section{Results}

Identification of placental proteins related to pathological development

To identify proteins that were differentially expressed in the placentas of normal and FGR patients, the 1198 identified proteins were analyzed on the Thermo-fisher Q-Exactive Orbitrap. Examination of the mass spectrometry data with Mascot (version 2.3.01) revealed that 95 proteins showed significant $(\mathrm{p}<0.05)$ differential expression between the normal and FGR placentas (Table 2).

Bioinformatics analysis of differentially expressed proteins

Ingenuity Pathway Analysis (IPA) was used to elucidate significant molecular networks and pathways associated with FGR. Comparison of the expression of 95 differentially expressed proteins revealed that 36 proteins were downregulated and 59 were upregulated in FGR, with a fold change of 1.2 (Table 2). The networks of interacting proteins and modules of functionally related proteins were show in Figure 1. These proteins were linked to two major molecular networks that are linked to erythropoiesis and oxidative stress (i.e., hemoglobin (A) and nicotinamide adenine dinucleotide phosphate (NADPH) oxidase (B) networks).

\section{Western blotting}

We validated the TMT results of the identified proteins with Western blotting using GAPDH as an internal reference. For this, we randomly selected the following five proteins (CSNK2B, GOSR2, HNRNPH2, SERPINA1 and SERPINA3) from the list of differentially expressed proteins. As shown in Figure 2, the Western blotting results were essentially in agreement with the results of the MS/MS analyses. 


\begin{tabular}{|c|c|c|}
\hline Cellular Physiolooy & Cell Physiol Biochem 2014;34:1701-1710 & \\
\hline and Biochemistry & $\begin{array}{l}\text { DOI: } 10.1159 / 000366371 \\
\text { Published onlIne: November 07, } 2014\end{array}$ & $\begin{array}{l}\text { (c) } 2014 \text { S. Karger AG, Basel } \\
\text { www.karger.com/cpb }\end{array}$ \\
\hline
\end{tabular}

Table 2. The list of differentially expressed proteins in human placenta from control and fetal growth restriction pregnancies. Fold change $=$ Controls $/$ fetal growth restriction (FGR). Fold Change $<0$ : The protein showed higher expression in the FGR placenta. Fold change> 0: The protein showed higher expression in the controls

\begin{tabular}{|c|c|c|}
\hline Protein ID & Protein names & $P$ value \\
\hline E7EQ34 & Golgi SNAP receptor complex member 2 (GOSR2) & $1.33 \mathrm{E}-09$ \\
\hline G3V5I3 & Alpha-1-antichymotrypsin member 3 (SERPINA3) & $1.33 \mathrm{E}-43$ \\
\hline 015347 & High mobility group protein B3 (HMGB3) High mobility group protein 2a (HMG-2a) High mobility group protein 4 (HMG-4) & $7.86 \mathrm{E}-26$ \\
\hline P01781 & Ig heavy chain V-III region GAL & 0.00045 \\
\hline P01859 & Ig gamma-2 chain $\mathrm{C}$ region (IGHG2) & $5.00 \mathrm{E}-43$ \\
\hline P02763 & Alpha-1-acid glycoprotein 1 (AGP 1) & $1.34 \mathrm{E}-20$ \\
\hline P05120 & Plasminogen activator inhibitor 2 (PAI-2) (SERPINB2) & $7.88 \mathrm{E}-21$ \\
\hline P06756 & Integrin alpha-V (ITGAV) & $9.05 \mathrm{E}-38$ \\
\hline P09466 & Progesterone-associated endometrial protein (PAEP) & $7.65 \mathrm{E}-06$ \\
\hline P22413 & Nucleotide pyrophosphatase [NPPS] & $1.75 \mathrm{E}-88$ \\
\hline P24043 & Laminin subunit alpha-2 (LAMA2) & 0 \\
\hline P27487 & Dipeptidyl peptidase 4 (DPP4) Adenosine deaminase complexing protein 2 (ADCP-2) & $1.55 \mathrm{E}-121$ \\
\hline Q13576 & Ras GTPase-activating-like protein (RASAL) & $5.16 \mathrm{E}-147$ \\
\hline Q8TDX7 & NimA-related protein kinase 7 (NEK7) & 0.00035 \\
\hline Q92973 & Transportin-1 (TRN1) & $5.50 \mathrm{E}-05$ \\
\hline Q9C005 & Protein dpy-30 homolog (DPY30) & $1.48 \mathrm{E}-16$ \\
\hline Q9GZM7 & Tubulointerstitial nephritis antigen-related protein (TIN-Ag-RP) & 3.18E-105 \\
\hline Q9Y3B3 & Transmembrane emp24 domain-containing protein 7 (TMED7) & 0.00024 \\
\hline Q5SRQ6 & Casein kinase 2, beta polypeptide (CSNK2B) & $6.47 \mathrm{E}-05$ \\
\hline B4E1Z4 & Complement factor B (CFB) & $2.69 \mathrm{E}-08$ \\
\hline J3KR44 & Ubiquitin thioesterase (OTUB1) & $1.20 \mathrm{E}-08$ \\
\hline P20936 & Ras GTPase-activating protein 1 (RASA1) & $1.46 \mathrm{E}-80$ \\
\hline P10599 & Thioredoxin (TXN) & $2.98 \mathrm{E}-11$ \\
\hline P55268 & Laminin subunit beta-2 (LAMB2) & 0 \\
\hline 014908 & Tax interaction protein 2 (TIP-2) & $1.11 \mathrm{E}-21$ \\
\hline $\mathrm{P} 62330$ & ADP-ribosylation factor 6 (ARF6) & $7.63 \mathrm{E}-08$ \\
\hline P55795 & Heterogeneous nuclear ribonucleoprotein $\mathrm{H} 2$ (HNRNPH2) & $6.75 \mathrm{E}-35$ \\
\hline Q00577 & Transcriptional activator protein Pur-alpha (TAPP) & $3.61 \mathrm{E}-07$ \\
\hline E9PRY8 & Elongation factor 1-delta (EEF1D) & $4.44 \mathrm{E}-12$ \\
\hline P02792 & Ferritin light chain (FTL) & $2.72 \mathrm{E}-17$ \\
\hline F5H4W9 & Serum paraoxonase/arylesterase 1 (PON1) & 0.0051527 \\
\hline P52597 & Heterogeneous nuclear ribonucleoprotein $\mathrm{F}$ (HNRNPF) & $1.71 \mathrm{E}-42$ \\
\hline Q6P1A2 & Lysophospholipid acyltransferase 5 (LPLAT 5) & $7.51 \mathrm{E}-06$ \\
\hline P31040 & Succinate dehydrogenase (SD) & $1.66 \mathrm{E}-23$ \\
\hline P23786 & Carnitine palmitoyltransferase II (CPT II) & $2.13 \mathrm{E}-15$ \\
\hline B7ZKJ8 & inter-alpha-trypsin inhibitor heavy chain H4 (ITIH4) & $6.01 \mathrm{E}-35$ \\
\hline P35555 & Fibrillin-1 (FBN1) & $3.83 \mathrm{E}-94$ \\
\hline F8W031 & Uncharacterized protein (Fragment) & $2.02 \mathrm{E}-19$ \\
\hline P05997 & Collagen alpha-2(V) (COL5A2) & $8.21 \mathrm{E}-05$ \\
\hline P04040 & Catalase (CAT) & $5.09 \mathrm{E}-56$ \\
\hline Q14019 & Coactosin-like protein (CLP) & $1.43 \mathrm{E}-14$ \\
\hline P05164 & Myeloperoxidase (MPO) & $1.64 \mathrm{E}-39$ \\
\hline P60903 & S100 calcium-binding protein $\mathrm{A} 10$ (S100A10) & $3.75 \mathrm{E}-39$ \\
\hline Q9HA64 & Fructosamine-3-kinase-related protein (FN3KRP) & 0.001366 \\
\hline Q4KWH8 & Phospholipase C-like protein 3 (PLC-L3) & $3.08 \mathrm{E}-06$ \\
\hline P14625 & Heat shock protein $90 \mathrm{kDa}$ beta member 1 (HSP90B1) Tumor rejection antigen 1 (TRA1) & $5.44 \mathrm{E}-270$ \\
\hline P49721 & Proteasome subunit beta type-2 (PSMB2) & $1.75 \mathrm{E}-06$ \\
\hline Q12805 & EGF-containing fibulin-like extracellular matrix protein 1 (EFEP1) & $7.27 \mathrm{E}-12$ \\
\hline P68871 & Hemoglobin subunit beta (HBB) & 0 \\
\hline 075306 & NADH dehydrogenase iron-sulfur protein 2 (NDUFS2) & $2.35 \mathrm{E}-15$ \\
\hline P01860 & Ig gamma-3 chain $\mathrm{C}$ region (IGHG3) & $5.23 \mathrm{E}-48$ \\
\hline P16452 & Erythrocyte membrane protein band 4.2 (EPB42) & 0.0057523 \\
\hline $\mathrm{P} 69892$ & Hemoglobin subunit gamma-2 (HBG2) & $1.54 \mathrm{E}-263$ \\
\hline Q96BM9 & ADP-ribosylation factor-like protein 8A (ARL8A) & $2.36 \mathrm{E}-25$ \\
\hline P07237 & Protein disulfide-isomerase (PDI) & 3.06E-189 \\
\hline MOQYNO & UPF0556 protein (C19orf10) & $2.79 \mathrm{E}-16$ \\
\hline P02751 & Fibronectin (FN) & 0 \\
\hline 043396 & Thioredoxin-like protein 1 (TXNL1) & 0.00043767 \\
\hline P21128 & Placental protein 11 (PP11) & $2.42 \mathrm{E}-24$ \\
\hline P16157 & Ankyrin-1 (ANK-1) & $1.02 \mathrm{E}-36$ \\
\hline Q14956 & Transmembrane glycoprotein NMB (GPNMB) & $1.17 \mathrm{E}-37$ \\
\hline P11277 & Spectrin beta chain (SPTB) & $1.60 \mathrm{E}-179$ \\
\hline Q9UNN8 & Endothelial protein C receptor (EPCR) & 0.00042307 \\
\hline Q9NRJ4 & Tubby-related protein 4 (TUBL4) & 0.014235 \\
\hline P46781 & 40 S ribosomal protein S9 (RPS9) & $1.25 \mathrm{E}-06$ \\
\hline Q04837 & Single-stranded DNA-binding protein (SSBP) & $3.02 \mathrm{E}-41$ \\
\hline M0QYS1 & 60 S ribosomal protein L13a (RPL13A) & $1.48 \mathrm{E}-05$ \\
\hline K7EROO & Phenylalanine--tRNA ligase alpha subunit t(FARSA) & $1.90 \mathrm{E}-07$ \\
\hline Q14554 & Protein disulfide-isomerase A5 (PDIA5) & $5.15 \mathrm{E}-06$ \\
\hline J3QQ67 & 60S ribosomal protein L18 (RPL18) & $5.93 \mathrm{E}-06$ \\
\hline P32119 & Natural killer cell-enhancing factor B Thioredoxin-dependent peroxide reductase 1 (TDPX1) & $3.55 \mathrm{E}-43$ \\
\hline Q92820 & Gamma-glutamyl hydrolase (GGH) & $1.89 \mathrm{E}-11$ \\
\hline P02549 & Spectrin alpha chain, erythrocytic 1 (SPTA1) & $2.30 \mathrm{E}-152$ \\
\hline $\mathrm{P} 61225$ & Ras-related protein Rap-2b (RAP2B) & $2.31 \mathrm{E}-09$ \\
\hline P11498 & Pyruvic carboxylase (PCB) & $1.75 \mathrm{E}-07$ \\
\hline P01009 & Alpha-1-antitrypsin [SERPINA1] & $2.30 \mathrm{E}-202$ \\
\hline P02730 & Anion exchange protein 1(AE1) Solute carrier family 4 member 1(SLC4A1) & 5.77E-181 \\
\hline P07093 & Glia-derived nexin (GDN) Peptidase inhibitor 7 (PI-7) (SERPINE2) & $3.60 \mathrm{E}-06$ \\
\hline P69891 & Hemoglobin subunit gamma-1 (HBG1) & $1.96 \mathrm{E}-257$ \\
\hline P01215 & Chorionic gonadotrophin subunit alpha (CGA) & 0.00053799 \\
\hline J3KN66 & Torsin-1A-interacting protein 1 (TOR1AIP1) & $1.03 \mathrm{E}-09$ \\
\hline 015554 & Intermediate conductance calcium-activated potassium channel protein 4 (SK4) & $5.12 \mathrm{E}-13$ \\
\hline Q3ZCQ8 & Mitochondrial import inner membrane translocase subunit TIM50 (TIM50) & $1.15 \mathrm{E}-07$ \\
\hline $\mathrm{P} 60842$ & Eukaryotic initiation factor 4A-I (EIF4A1) & $4.47 \mathrm{E}-90$ \\
\hline P37108 & Signal recognition particle $14 \mathrm{kDa}$ protein (SRP14) & $5.58 \mathrm{E}-10$ \\
\hline Q14839 & Chromodomain-helicase-DNA-binding protein 4 (CHD-4) & $8.35 \mathrm{E}-08$ \\
\hline C9JV77 & Alpha-2-HS-glycoprotein (A2HS) & 4.07E-11 \\
\hline P69905 & Hemoglobin subunit alpha (HBA) & $2.14 \mathrm{E}-136$ \\
\hline Q9BU23 & Lipase maturation factor 2 (LMF2) & $1.75 \mathrm{E}-15$ \\
\hline Q02543 & 60S ribosomal protein L18a (RPL18A) & 0.00027036 \\
\hline Q13361 & Microfibrillar-associated protein 5 (MFAP-5) Microfibril-associated glycoprotein 2(MAGP-2) & 0.00018138 \\
\hline 000442 & RNA terminal phosphate cyclase domain-containing protein 1 (RTC1) & $9.39 \mathrm{E}-06$ \\
\hline G3V1K3 & Paraoxonase 2(PON2) & $8.93 \mathrm{E}-22$ \\
\hline B4DR87 & Procollagen-lysine,2-oxoglutarate 5-dioxygenase 1 (PLOD1) & $1.06 \mathrm{E}-07$ \\
\hline Q86XP3 & ATP-dependent RNA helicase DDX42(DDX42) & $3.25 \mathrm{E}-05$ \\
\hline
\end{tabular}




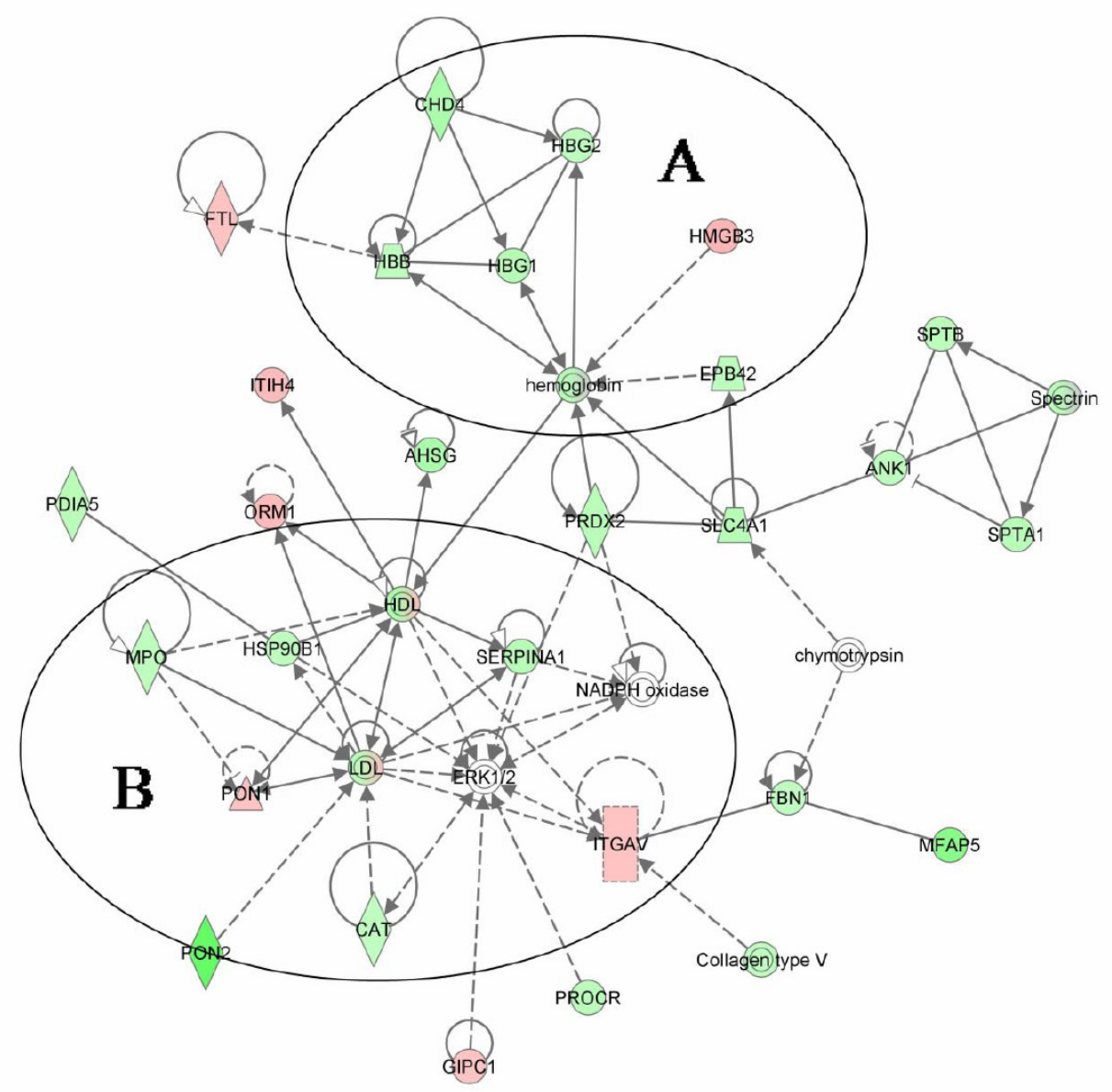

Fig. 1. Schematic representation of network using Ingenuity pathway analysis (IPA) of differentially expressed genes. 35 of 95 total differentially expressed proteins are linked to two major molecular networks: erythropoiesis and oxidative stress which had the highest significant scores (A: hemoglobin network; B: nicotinamide adenine dinucleotide phosphate (NADPH) oxidase network). Relationships are defined in the legends. Green is indicative of genes going up and red depicts genes suppressed in the FGR placenta.

\section{Discussion}

FGR is a major complication of pregnancy and affects up to $10 \%$ of all pregnancies [1]. It is the main cause of intrauterine fetal death and the second leading cause of death in the neonatal period [2]. Placenta is known as a critical determinant of fetal growth. Many previous studies have shown that structural and functional alterations in the placenta from FGR pregnancies might affect fetal growth and development. However, the fundamental mechanisms underlying these defects are poorly understood [3-6]. Therefore, we attempted to gain a comprehensive map of the proteins that are differentially expressed in FGR placentas.

Here, we carried out a comparative proteome study to determine the proteins that are differentially expressed in human placentas of normal and FGR pregnancies. A total of 1198 unique proteins expressed in the human placenta were identified with high confidence. Of these, 95 were found to be differentially expressed between these two groups. Ingenuity Pathway Analysis (IPA) was used to elucidate the significant molecular networks and pathways associated with FGR. Thirty five of these 95 total differentially expressed proteins 
Fig. 2. Western blotting analyses and proteome profiles of five proteins from fetal growth restriction and normal placentas. (A) Western blotting analyses of the five proteins. (B) Corresponding contrast analyses of the blots in A. (C) Proteome profiles of the five proteins in total protein extracts with LC-MS/MS analyses. Student's T-test was used to generate $\mathrm{p}$ values. Significant difference was recognized as a $\mathrm{p}$ value less than 0.05 .

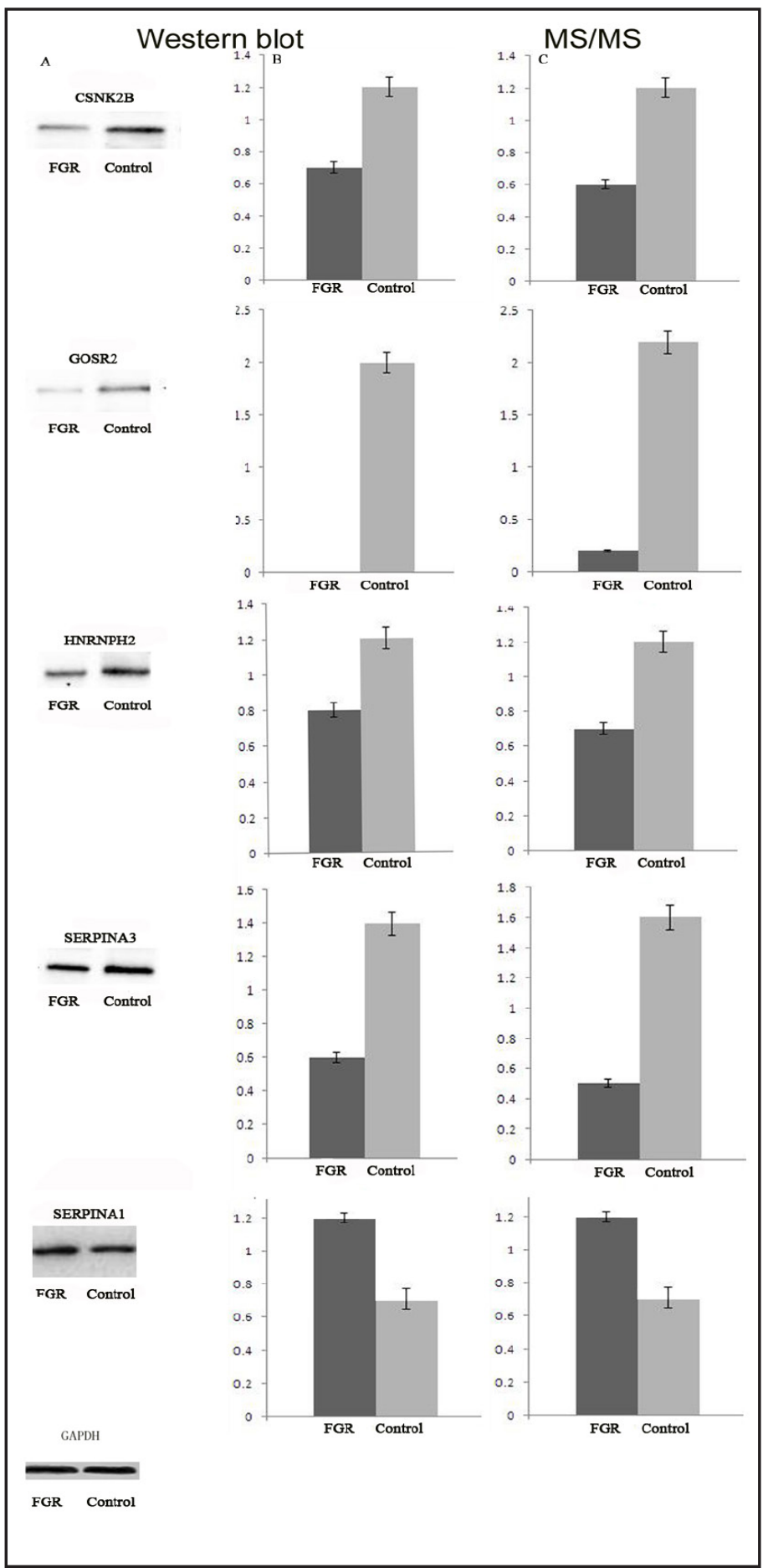

are linked to two major molecular networks that are linked to erythropoiesis and oxidative stress.

Several proteins such as NADPH oxidase, low-density lipoprotein (LDL), and SERPINA1 play critical roles in the pathological development of FGR. NADPH oxidase is an enzyme complex that can generate large amounts of reactive oxygen species (ROS). They are generated at the maternal-fetal interface at the decidual, trophoblast, and mesenchymal levels. Physiological ROS levels play an important regulatory role through various signaling transduction pathways in uterine function, embryogenesis, embryonic implantation, and 
feto-placental development $[16,31,32]$. However, the imbalance between antioxidants and ROS production (oxidative stress) is a causative agent in FGR [11-13]. Nutritional and environmental factors are the sources of oxidative stress [33, 34]. There is considerable evidence that FGR is associated with oxidative stress [35-37]. SERPINA1, also known as alpha-1 antitrypsin (AAT), is an acute phase protein and one member of the serpin superfamily of serine protease inhibitors. SERPINA1 has been shown to be a broad-spectrum anti-inflammatory, immunomodulatory, anti-infective and tissue-repair molecule. Moreover, SERPINA1 can increase LDL binding and uptake, and upregulate the levels of LDL receptors $[38,39]$. However, decreased SERPINA1 activity, which is associated with oxidative stress, has been reported in FGR placentas [17-19]. SERPINA1 has been shown to be oxidized by peroxide lipids and various oxidants, and oxidized SERPINA1 has multiple effects on cytokine expression, generation of ROS, and intracellular lipid metabolism. Furthermore, oxidized SERPINA1 can release elastase, which may induce vascular abnormalities and stimulate NADPH oxidase, catalyzing the production of superoxides, which in turn causes direct oxidative damage to biomolecules, including SERPINA1 itself [40-42]. All in all, NADPH oxidase, LDL, and SERPINA1 are all associated with oxidative stress, which plays an important role in the pathological changes observed in FGR placentas. Several studies have suggest that using antioxidants (e.g., vitamins $\mathrm{C}$ and $\mathrm{E}$ ) to treat pregnancies that are at high risk of FGR have shown positive effects of reducing the incidence of maternal disease and improving the prognosis of fetuses with FGR [43-45].

Studies have shown that hypoxia can enhance erythropoiesis to improve the oxygen carrying and buffering capacities by increasing the erythrocyte mass and hemoglobin concentration, and high hemoglobin concentrations have been associated with FGR [46-48]. In this work, HBA1, HBA2, HBG1, HBG2, and HBB were all found upregulated in the placenta of FGR. Therefore, abnormal erythropoiesis may be one cause of FGR.

Apoptosis is an essential feature of normal placental development but is notably exaggerated in association with some pregnancy complications [49], such as FGR [14]. DDX42 is a putative ATP-dependent RNA helicase implicated in cellular growth and apoptosis. It is a major apoptosis inducer known to enhance p53 transactivation of proapoptotic genes [23]. In this study, DDX42 was approximately 4.5-fold upregulated. At present, the pathological mechanism underlying increased cell apoptosis in FGR is still not understood. Crocker et al. found an increased susceptibility to apoptosis of primary trophoblasts isolated from patients with FGR [15]. In any case, the end result would be placental dysfunction and suboptimal pregnancy outcomes.

In summary, through comparative proteome analysis of the placentas of normal and FGR pregnancies, we constructed a protein expression profile; identified modules of functionally related proteins; and outlined important proteins that play key roles in the incidence and development of FGR, such as NADPH oxidase, SERPINA1, and DDX42. Further functional analyses of these differentially expressed proteins will help in understanding the critical biological processes and discovery of potential biomarkers and therapeutic targets, and eventually improve the prognosis of fetuses with FGR.

\section{Acknowledgement}

This work was supported by Grant 81100436 from the National Natural Science Foundation of China; Grant SKLRM-KF-201109 from the State Key Laboratory of Reproductive Medicine Fund; grant 2013NJMU142 from the Nanjing Medical University Foundation; grant YKK14 from Nanjing Medical Development Project.

\section{Disclosure Statement}

All authors have no conflicts of interest to declare. 


\section{References}

1 Hung TH, Skepper JN, Charnock-Jones DS, Burton GJ: A potent inducer of apoptotic changes in the human placenta and possible etiological factor in Preeclampsia. Circ Res 2002;90:1274-1281.

-2 Radulescu L, Ferechide D, Popa F: The importance of fetal gender in intrauterine growth restriction. J Med Life 2013;6:38-39.

3 Cox P, Marton T: Pathological assessment of intrauterine growth restriction. Best Pract Res Clin Obstet Gynaecol 2009;23:751-764.

4 Spinillo A, Gardella B, Bariselli S, Alfei A, Silini E, Dal Bello B: Placental histopathological correlates of umbilical artery Doppler velocimetry in pregnancies complicated by fetal growth restriction. Prenat Diagn 2012;32:1263-1272.

5 Lyall F, Robson SC, Bulmer JN: Spiral artery remodeling and trophoblast invasion in preeclampsia and fetal growth restriction: relationship to clinical outcome. Hypentension 2013; 62:1046-1054.

$>6$ Longtine MS, Chen B, Odibo AO, Zhong Y, Nelson DM: Villous trophoblast apoptosis is elevated and restricted to cytotrophoblasts in pregnancies complicated by preeclampsia, IUGR, or preeclampsia with IUGR. Placenta 2012;33:352-359.

7 Biswas S, Adhikari A, Chattopadhyay JC, Ghosh SK: Histological changes of placentas associated with intrauterine growth restriction of fetuses: a case control study. Nepal Med Coll J 2012;14:18-24.

8 Fowden, AL, Forhead, AJ, Coan, PM. Burton GJ: The Placenta and Intrauterine Programming . J Neuroendocrinol 2008;20:439-450.

9 Mifsud W, Sebire NJ: Placental Pathology in Early-Onset and Late-Onset Fetal Growth Restriction. Fetal Diagn Ther 2014;36:117-128.

10 Todros T, Sciarrone A, Piccoli E, Guiot C, Kaufmann P, Kingdom J: Umbilical Doppler waveforms and placental villous angiogenesis in pregnancies complicated by fetal growth restriction. Obstet Gynecol 1999;93:499-503.

11 Gupta S, Agarwal A, Banerjee J, Alvarez JG: The role of oxidative stress in spontaneous abortion and recurrent pregnancy loss: a systematic review. Obstet Gynecol Surv 2007;62:335-347.

12 Reid MV, Murray KA, Marsh ED, Golden JA, Simmons RA, Grinspan JB: Delayed myelination in an intrauterine growth retardation model is mediated by oxidative stress upregulating bone morphogenetic protein 4. J Neuropathol Exp Neurol 2012;71:640-653.

-13 Al-Gubory KH, Fowler PA, Garrel C: The roles of cellular reactive oxygen species, oxidative stress and antioxidants in pregnancy outcomes. Int J Biochem Cell Biol 2010;42:1634-1650.

14 Ishihara N, Matsuo H, Murakoshi H, Laoag-Fernandez JB, Samoto T, Maruo T: Increased apoptosis in the syncytiotrophoblast in human term placentas complicated by either preeclampsia or intrauterine growth retardation. Am J Obstet Gynecol 2002;186:158-166.

15 Crocker IP, Cooper S, Ong SC, Baker PN: Differences in apoptotic susceptibility of cytotrophoblasts and syncytiotrophoblasts in normal pregnancy to those complicated with preeclampsia and intrauterine growth restriction. Am J Pathol 2003;162:637-643.

16 Bevilacqua E, Gomes SZ, Lorenzon AR, Hoshida MS, Amarante-Paffaro AM: NADPH oxidase as an important source of reactive oxygen species at the mouse maternal-fetal interface: putative biological roles. Reprod Biomed Online 2012;25:31-43 .

17 Pecks U, Caspers R, Schiessl B, Bauerschlag D, Piroth D, Maass N, Rath W: The evaluation of the oxidative state of low-density lipoproteins in intrauterine growth restriction and preeclampsia. Hypertens Pregnancy 2012;31:156-165.

18 Karowicz-Bilinska A, Kedziora-Kornatowska K, Bartosz G: Indices of oxidative stress in pregnancy with fetal growth restriction. Free Radic Res 2007;41: 870-873.

19 Pecks U, Rath W, Caspers R, Sosnowsky K, Ziems B, Thiesen HJ, Maass N, Huppertz B: Oxidatively modified LDL particles in the human placenta in early and late onset intrauterine growth restriction. Placenta 2013;34:1142-1149.

20 Randhawa RS: The insulin-like growth factor system and fetal growth restriction. Pediatr Endocrinol Rev 2008;6:235-240.

21 Maulik D, Frances Evans J, Ragolia L: Fetal growth restriction: pathogenic mechanisms. Clin Obstet Gynecol 2006;49:219-227.

22 Huang L, Shen Z, Xu Q Huang X, Chen Q, Li D: Increased levels of microRNA-424 are associated with the pathogenesis of fetal growth restriction. Placenta 2013;34: 624-627.

23 Uhlmann-Schiffler H, Kiermayer S, Stahl H: The DEAD box protein Ddx42p modulates the function of ASPP2, a stimulator of apoptosis. Oncogene 2009;28: 2065-2073.

24 Ishihara N, Matsuo H, Murakoshi H, Laoag-Fernandez JB, Samoto T, Maruo T: Increased apoptosis in the syncytiotrophoblast in human term placentas complicated by either preeclampsia or intrauterine growth 
retardation. Am J Obstet Gynecol 2002;186:158-166.

25 Heazell AE, Sharp AN, Baker PN, Crocker IP: Intra-uterine growth restriction is associated with increased apoptosis and altered expression of proteins in the $\mathrm{p} 53$ pathway in villous trophoblast. Apoptosis 2011;16:135-144.

26 Yui J, Garcia-Lloret M, Wegmann TG, Guilber LJ: Cytotoxicity of tumour necrosis factor-alpha and gammainterferon against primary human placental trophoblasts. Placenta 1994;15:819-835.

27 Wadsack C, Tabano S, Maier A, Hiden U, Alvino G, Cozzi V, Hüttinger M, Schneider WJ, Lang U, Cetin I, Desoye G: Intrauterine growth restriction is associated with alterations in placental lipoprotein receptors and maternal lipoprotein composition. Am J Physiol Endocrinol Metab 2007;292:E476-484.

28 Merchant SJ, Crocker IP, Baker PN, Tansinda D, Davidge ST, Guilbert LJ: Matrix metalloproteinase release from placental explants of pregnancies complicated by intrauterine growth restriction. J Soc Gynecol Investig 2004;11:97-103.

29 Nuzhat Ahmed, Gillian Barker, Karen Oliva, David Garfin, Kenneth Talmadge, Harry Georgiou, Michael Quinn, Greg Rice: An approach to remove albumin for the proteomic analysis of low abundance biomarkers in human serum. Proteomics 2003;3:1980-1987.

30 Xu B, Hua J, Zhang Y, Jiang X, Zhang H, Ma T, Zheng W, Sun R, Shen W, Sha J, Cooke HJ, Shi Q: Proliferating cell nuclear antigen (PCNA) regulates primordial follicle assembly by promoting apoptosis of oocytes in fetal and neonatal mouse ovaries. PloS one 2011;6:e16046.

-31 Ushio-Fukai M: Localizing NADPH oxidase-derived ROS. Sci STKE 2006;2006:re8.

- 32 Agarwal A, Gupta S, Sekhon L, Shah R: Redox considerations in female reproductive function and assisted reproduction: from molecular mechanisms to health implications. Antioxid Redox Signal 2008;10:13751403.

-33 Luo Z C, Fraser W D, Julien P, Deal CL, Audibert F, Smith GN, Xiong X, Walker M: Tracing the origins of "fetal origins" of adult diseases: programming by oxidative stress. Med Hypotheses 2006;66:38-44.

-34 Chavatte-Palmer P, Al Gubory K, Picone O, Heyman Y: Maternal nutrition: effects on offspring fertility and importance of the periconceptional period on long-term development. Gynecol Obstet Fertil 2008;36:920929.

-35 Mert I, Oruc AS, Yuksel S, Cakar ES, Buyukkagnici U, Karaer A, Danisman N: Role of oxidative stress in preeclampsia and intrauterine growth restriction. J Obstet Gynaecol Res 2012;38:658-664.

-36 Stanley J L, Andersson I J, Hirt C J, Moore L, Dilworth MR, Chade AR, Sibley CP, Davidge ST, Baker PN: Effect of the anti-oxidant tempol on fetal growth in a mouse model of fetal growth restriction. Biol Reprod 2012;87:251-258.

-37 Biri A, Bozkurt N, Turp A, Kavutcu M, Himmetoglu O, Durak I: Role of oxidative stress in intrauterine growth restriction. Gynecol Obstet Invest 2007;64:187-192.

- 38 Serres F, Blanco I: Role of alpha-1 antitrypsin in human health and disease. J Intern Med 2014. doi: 10.1111/joim.12239.

-39 Janciauskiene S, Lindgren S: Human monocyte activation by cleaved form of alpha-1-antitrypsin. Eur J Biochem 1999;265:875-882.

40 Ueda M, Mashiba S, Uchida K: Evaluation of oxidized alpha-1-antitrypsin in blood as an oxidative stress marker using anti-oxidative $\alpha 1$-AT monoclonal antibody. Clin Chim Acta 2002; 317:125-131.

41 Mohsenin V, Gee JL: Oxidation of $\alpha 1$-proteinase inhibitor: role of lipid peroxidation products. J Appl Physiol 1989;66:2211-2215.

42 Moraga F, Janciauskiene S: Activation of primary human monocytes by the oxidized form of $\alpha 1$-antitrypsin. J Biol Chem 2000;275:7693-7700.

43 Karowicz-Bilińska A, Suzin J, Sieroszewski P: Evaluation of oxidative stress indices during treatment in pregnant women with intrauterine growth retardation. Med Sci Monit 2002;8:CR211-216.

44 Spong C Y, Abebe D T, Gozes I, Brenneman DE, Hill JM: Prevention of fetal demise and growth restriction in a mouse model of fetal alcohol syndrome. J Pharmacol Exp Ther 2001;297:774-779.

-45 Miller SL, Yawno T, Alers NO, Castillo-Melendez M, Supramaniam VG, VanZyl N, Sabaretnam T, Loose JM, Drummond GR,Walker DW, Jenkin G, Wallace EM: Antenatal antioxidant treatment with melatonin to decrease newborn neurodevelopmental deficits and brain injury caused by fetal growth restriction. J Pineal Res 2014;56:283-294.

46 Weiner CP, Williamson RA: Evaluation of severe growth retardation using cordocentesis-hematologic and metabolic alterations by etiology. Obstet Gynecol 1989;73:225-229.

47 Steer PJ: Maternal hemoglobin concentration and birth weight. Am J Clin Nutr 2000;71:1285s-1287s.

- 48 Salas SP, Marshall G, Gutiérrez BL, Rosso P: Time course of maternal plasma volume and hormonal changes in women with preeclampsia or fetal growth restriction. Hypertension 2006;47:203-208.

49 Sharp AN, Heazell AE, Crocker IP, Mor G: Placental apoptosis in health and disease. Am J Reprod Immunol 2010;64:159-169. 